\title{
Serum neurofilament light chains in MS
}

\section{Association with the Timed Up and Go}

Gilles Allali, MD, PhD, Jens Kuhle, MD, Gautier Breville, MD, David Leppert, MD, Stephane Armand, PhD, and Patrice H. Lalive, MD

Neurol Neuroimmunol Neuroinflamm 2020;7:e895. doi:10.1212/NXI.0000000000000895

\author{
Correspondence \\ Dr. Allali \\ Gilles.Allali@cuge.ch
}

\section{Abstract}

\section{Objective}

This cross-sectional study aims to assess the association between neuroaxonal damage assessed by serum neurofilament light chain (sNfL) and the Timed Up and Go (TUG) — a reliable and rapid measure of global neurologic disability — in patients with MS.

\section{Methods}

A total of 41 consecutive patients with MS (38.0 \pm 10.4 years; $57 \%$ women) with low level of disability (Expanded Disability Status Scale [EDSS] score 0-3) (EDSS score 1.0, interquartile range $[\mathrm{IQR}]$ 0.0-2.0) were included in this study. The TUG and sNfL were measured in a 6-month interval, together with a comprehensive neuropsychological and quantitative gait evaluation. The association of sNfL (dependant variable) with TUG, and other gait, cognitive, and behavioral measures (independent variables) were evaluated with multiple linear regressions adjusted for age, sex, and EDSS score.

\section{Results}

The sNfL concentration was $23.51 \mathrm{pg} / \mathrm{mL}$ (IQR $16.51-32.21 \mathrm{pg} / \mathrm{mL}$ ), and the mean TUG was $9.27 \pm 1.70$ seconds. Only the TUG was associated with sNfL ( $\beta=0.021$; 95\% CI 0.003-0.037; $p=0.022$ ) (after adjusting for age, sex, and EDSS score), whereas this was not the case for gait and neuropsychological measures.

\section{Conclusions}

The TUG - an easy and unexpansive measure of disability - is associated with the degree of neuroaxonal damage, as measured by sNfL, in patients with MS with low level of disability. These findings confirm the validity of the TUG as a reliable bedside measure of global neurologic disability as a result of neuroaxonal damage.

From the Division of Neurology (G.A., G.B., P.H.L.), Department of Clinical Neurosciences, Geneva University Hospitals and Geneva University, Switzerland; Department of Neurology (G.A.), Albert Einstein College of Medicine, Yeshiva University, New York; Neurologic Clinic and Policlinic (J.K., D.L.), Departments of Medicine, Biomedicine and Clinical Research, University Hospital Basel and University of Basel; Willy Taillard Laboratory of Kinesiology (S.A.), Geneva University Hospitals and University of Geneva; Division of Laboratory Medicine (P.H.L.), Department of Genetic and Laboratory Medicine, Geneva University Hospitals; and Department of Pathology and Immunology (P.H.L.), Faculty of Medicine, University of Geneva, Switzerland. 


\section{Glossary}

EDSS = Expanded Disability Status Scale; IQR = interquartile range; NfL = neurofilament light chain; sNfL = serum NfL; TMT $=$ Trail Making Test; TUG $=$ Timed Up and Go.

The Timed Up and Go (TUG) is a rapidly operable and widely used test of mobility and risk of falls in neurologic settings and has been recently validated in MS as a measure of functional mobility. ${ }^{1}$ The TUG is correlated with common measures of functional mobility in MS, such as the timed 25-foot walk or the Multiple Sclerosis Walking Scale-12 score. In comparison to other measures of functional mobility, the TUG captures elements of the everyday life, such as sitting, standing, and turning around, ${ }^{1}$ and can be quickly performed by clinicians during the neurologic examination even in a limited office space. In a previous study, we have demonstrated that the TUG was correlated with gait parameters, as well as with cognitive performances, and is considered a sensitive marker for quantifying disability in early stage of MS. ${ }^{2}$ The TUG has been associated with gray and white matter atrophy in patients with $\mathrm{MS},{ }^{3}$ but the relationship between the TUG and markers of neuroaxonal damage has not been evaluated.

Neurofilament light chain (NfL), a product of the scaffolding proteins of the neuronal cytoskeleton, represents a biomarker of axonal damage. ${ }^{4}$ Serum NfL ( $\mathrm{sNfL}$ ) has been validated as a reliable marker for present and potentially future disability in MS, ${ }^{5}$ including clinically isolated syndrome and early MS. ${ }^{6}$ However, the association between $\mathrm{SNfL}$ and a bedside clinical test of disability, such as the TUG, has never been tested in patients with MS with low disability.

This cross-sectional study aims to assess the association between a biological marker of neuroaxonal damage (assessed by sNfL) and disability (measured by the TUG) in patients with MS with low disability. As the TUG represents a good measure of gait and cognitive disability, and sNfL has been associated with fully established disability in MS, we aimed at evaluating whether the TUG will be associated with sNfL in early phases of disability. Establishing the association between sNfL and TUG in patients with MS with low level of disability will provide an important clue for clinicians to quickly evaluate the level of disability associated with axonal damage.

\section{Methods}

\section{Participants}

Forty-one consecutive outpatients with relapsing-remitting MS (38.0 \pm 10.4 years; $57 \%$ female) were included in the protocol. Exclusion criteria were acute medical illness in the past month, neurologic and psychiatric diseases except MS, orthopedic or rheumatologic condition affecting walking, Expanded Disability Status Scale (EDSS) score $>3$, and an interval of $>6$ months between sNfL measurement and clinical assessment. All patients were stable under the same treatment for at least 3 months before clinical assessment (table 1).

\section{Serum sampling and sNfL measurements}

Serum samples were centrifuged at $2,000 \mathrm{~g}$ for 10 minutes at room temperature and stored at $-80^{\circ} \mathrm{C}$ within 2 hours of collection. Serum NfL levels were determined by single molecule array assay as previously described. ${ }^{7}$

\section{TUG test}

The main outcome variable was the mean \pm SD of the time (seconds) of the TUG described by Podsiadlo and Richardson. The TUG was performed at self-selected speed in a welllit environment: the patients were asked to stand up, walk $3 \mathrm{~m}$, turn around, walk back to the chair, and sit down.

\section{Gait and neuropsychological assessment}

Patients were asked to walk on a 10-m walkway at their selfselected speed, as previously described. ${ }^{8}$ Spatiotemporal gait parameters were computed using Matlab 2015b (MathWorks, Natick, MA) based on the trajectories of heel reflective markers $(14 \mathrm{~mm})$ recorded at $100 \mathrm{~Hz}$ by an optoelectronic system (12 cameras, Vicon Mx3+; Vicon Peak) and reconstructed by Nexus 1.8.5 (Vicon Peak).

The neuropsychological assessment focused on the cognitive domains commonly disturbed in MS: memory (Selective Reminding Test ), executive functions (verbal fluency task, Stroop, Trail Making Test (TMT) B, and divided attention and working memory subtests from Test of Attention Performance), attention (digit span and symbol digit modalities test from the Wechsler Adult Intelligence Scale-III, Stroop dot condition, and TMT A), fear of falling by the 16-item Falls Efficacy Scale-International, anxiety and depression assessed by the Hospital Anxiety and Depression scale, and were assessed by the same neuropsychologist.

\section{Statistics}

The participants' characteristics were summarized using mean values and SDs or frequencies and percentages, as appropriate. Multiple linear regressions were performed to examine the association between the sNfL (independent variable) and TUG, and other gait, cognitive, and behavioral parameters (dependent variables) adjusted for age, sex, and EDSS score. All statistics were performed using SPSS (version 22.0; SPSS, Inc., Chicago, IL).

\section{Standard protocol approvals, registrations, and patient consents}

The Geneva University Hospitals Committee on Human Research approved the research protocol, and informed consent was obtained from all participants. 
Table 1 Clinical characteristics of patients with relapsingremitting MS $(n=41)$

\begin{tabular}{ll}
\hline Age, $\mathbf{y}$, mean \pm SD & $38.0 \pm 10.4$ \\
\hline Female, $\mathbf{n}(\%)$ & $26(57)$ \\
\hline Education, ${ }^{a} \mathbf{y}$, mean \pm SD & $15.2 \pm 2.6$ \\
\hline EDSS score (10), mean \pm SD (range) & $1.13 \pm 0.98(0-3)$ \\
\hline Disease duration, mo, mean \pm SD & $33.2 \pm 34.7$ \\
\hline Since diagnosis & $52.5 \pm 44.1$ \\
\hline Since first symptoms & $17(41)$ \\
\hline Treatment, $\mathbf{n}$ (\%) & $8(20)$ \\
\hline Fingolimod & $6(15)$ \\
\hline Natalizumab & $5(12)$ \\
\hline Dimethyl fumarate & $1(2)$ \\
\hline Interferon $\beta-1 \mathbf{a}$ & $5(12)$ \\
\hline Glatiramer &
\end{tabular}

Abbreviation: EDSS = Expanded Disability Status Scale.

${ }^{a}$ Assessed with the number of years at school.

\section{Data availability}

Anonymized data that are not published in this article will be made available on request from any qualified investigator after the approval by the Institutional Review Board of the Geneva University Hospitals.

\section{Results}

Clinical characteristics of the 41 patients with MS are summarized in table 1. The median EDSS score was 1.0 (interquartile range $[\mathrm{IQR}]$ 0.0-2.0), with a mean disease duration of less than 3 years (time since diagnosis: $33.2 \pm 34.7$ months). The sNfL concentration was $23.51 \mathrm{pg} / \mathrm{mL}$ (IQR $16.51-32.21 \mathrm{pg} / \mathrm{mL}$ ), without any difference between male and female $(p=0.229)$. Gait parameters were normal (gait speed: $1.30 \pm 0.18 \mathrm{~m} / \mathrm{s}$; stride time variability: $1.75 \% \pm 1.10 \%)$. The mean TUG was $9.27 \pm$ 1.70 seconds. Cognitive and behavioral performances are reported in table e-1 (links.lww.com/NXI/A318).

Among spatiotemporal gait parameters, cognitive and behavioral performances, only the TUG was associated with sNfL in the univariable model; this association was sustained after adjusting for age, sex, and EDSS score $(\beta=0.021$; $95 \%$ CI 0.003-0.037; $p=0.022$ ) (table 2) —an increase of $1 \mathrm{pg} / \mathrm{mL}$ of NfL concentration was associated with a TUG increase of 0.02 seconds.

\section{Discussion}

We show that sNfL, a promising serum biomarker of neuroaxonal damage in $M S$, is associated with the TUG. We observed this association in patients with MS with low disability.

Estimating the extent of neuroaxonal damage in very early disease stages represents a challenge. Here, we provide evidence that the duration of the TUG is associated with the severity of neuroaxonal injury quantified by sNfL. ${ }^{4}$ CSF NFL levels have been associated with attentional control in patients with MS. ${ }^{9}$ Also, attentional performances are associated with the duration of the TUG in older adults and in patients with

Table 2 Association between serum neurofilament light chain levels ${ }^{a}$ (independent variable) and Timed Up and Go, and other gait, cognitive, and behavioral variables (dependent variables) adjusted for age, sex, and EDSS score $(n=41)$

\begin{tabular}{|c|c|c|c|c|}
\hline & \multicolumn{4}{|c|}{ Multivariable } \\
\hline & $\beta$ & $95 \% \mathrm{Cl}$ & $p$ Value & $R^{2}$ \\
\hline Timed Up and Go & 0.021 & 0.003 to 0.037 & 0.022 & 0.30 \\
\hline EDSS score & 0.009 & -0.002 to 0.019 & 0.112 & - \\
\hline \multicolumn{5}{|l|}{ Gait } \\
\hline Gait speed & -0.001 & -0.002 to 0.001 & 0.568 & - \\
\hline Stride time & 0.000 & -0.001 to 0.001 & 0.529 & - \\
\hline Stride time variability & 0.012 & -0.001 to 0.024 & 0.060 & - \\
\hline Stride length & 0.000 & -0.002 to 0.001 & 0.576 & - \\
\hline Step width & 0.000 & -0.000 to 0.000 & 0.587 & - \\
\hline \multicolumn{5}{|l|}{ Cognition } \\
\hline Memory & -0.011 & -0.027 to 0.005 & 0.168 & - \\
\hline Executive functions & -0.093 & -0.210 to 0.023 & 0.112 & - \\
\hline Attention & 0.080 & -0.014 to 0.173 & 0.092 & - \\
\hline \multicolumn{5}{|l|}{ Behavior } \\
\hline Fatigue & 0.234 & -0.189 to 0.657 & 0.267 & - \\
\hline Fear of falling & 0.000 & -0.043 to 0.042 & 0.993 & - \\
\hline Anxiety & -0.017 & -0.060 to 0.025 & 0.413 & - \\
\hline Depression & 0.007 & -0.027 to 0.042 & 0.670 & - \\
\hline
\end{tabular}

Abbreviations: EDSS = Expanded Disability Status Scale; IQR = interquartile range; SRT = selective reminding test; $\mathrm{TMT}=$ Trail Making Test.

Bold text indicates significant $p$ values.

Memory domain includes SRT; we only present the regression with the SRT (delayed recall) because other tests assessing the memory domain were also not significant.

Executive functions include verbal fluency (semantic and phonemic), Stroop, and TMT part B; we only present the regression with the semantic verbal fluency because other tests assessing the executive function domain were also not significant.

Attention includes Wechsler Adult Intelligence Scale-III (digit span and symbol digit modalities test) and TMT part A (TMT-A); we only present the regression with the TMT-A because other tests assessing the attention domain were also not significant.

Fatigue was assessed by the modified fatigue impact scale.

Fear of falling was assessed by 16-item Falls Efficacy Scale-International.

Anxiety and depression were assessed by the Hospital Anxiety and Depression Scale.

a Serum neurofilament light chain (median): 23.51 pg/mL (IQR 16.51-32.21 pg/mL). 
$\mathrm{MS},{ }^{2}$ in addition to its strong association with the EDSS score and gait disability. ${ }^{1}$ The multimodality of the TUG that integrates several components of both gait and cognitive parameters may explain why the TUG is the only one measure (among spatiotemporal gait parameters and cognitive performances) that was associated with sNfL in our study. Key phases of the TUG, such as the turn-to-walk and turn-to-sit phases, are associated with specific cognitive domains, such as executive function and visuospatial performance. ${ }^{10}$ The TUG, which can be performed in the doctor office without any expansive equipment other than a stopwatch, provides important insight to the clinician to the extent of axonal damage in their patients with MS.

Our study has some limitations. We only include patients with MS with low disability (EDSS score $\leq 3$ ), preventing the generalization of the study findings to the entire MS population. Although the association between sNfL and TUG has been adjusted on age, sex, and EDSS score, the small number of participants prevents to adjust our association on other variables, such as falls or fear of falling. Future studies should verify whether this association between sNfL and TUG remains significant for patients with MS with increased levels of disability (EDSS score $>3$ ).

In conclusion, we demonstrated an association between a biological marker of neuroaxonal damage-measured by sNfL_- and the TUG in patients with MS with low disability. These findings may help the clinicians to estimate and monitor the progression of the disease.

\section{Acknowledgment}

The authors are grateful to the patients for their participations to the study.

\section{Study funding}

This study was supported by a grant from the Geneva University Hospitals (PRD 18-2016-II), the Swiss Multiple Sclerosis Society, Swiss National Science Foundation (310030_ 176078), and the Fondation privée des HUG.

\section{Disclosure}

The authors report no disclosures. Go to Neurology.org/NN for full disclosures.

\section{Publication history}

Received by Neurology: Neuroimmunology \& Neuroinflammation June 8, 2020. Accepted in final form August 31, 2020.

\begin{tabular}{|c|c|c|}
\hline Name & Location & Contribution \\
\hline $\begin{array}{l}\text { Gilles } \\
\text { Allali, MD, } \\
\text { PhD }\end{array}$ & $\begin{array}{l}\text { Geneva University } \\
\text { Hospitals, } \\
\text { Switzerland }\end{array}$ & $\begin{array}{l}\text { Designed and conceptualized the } \\
\text { study; analyzed the data; major role } \\
\text { in the acquisition of data; and } \\
\text { drafted the manuscript for } \\
\text { intellectual content }\end{array}$ \\
\hline $\begin{array}{l}\text { Jens Kuhle, } \\
\text { MD, PhD }\end{array}$ & $\begin{array}{l}\text { University Hospital } \\
\text { Basel, Switzerland }\end{array}$ & $\begin{array}{l}\text { Interpreted the data and revised } \\
\text { the manuscript for intellectual } \\
\text { content }\end{array}$ \\
\hline $\begin{array}{l}\text { Gautier } \\
\text { Breville, } \\
\text { MD }\end{array}$ & $\begin{array}{l}\text { Geneva University } \\
\text { Hospitals, } \\
\text { Switzerland }\end{array}$ & $\begin{array}{l}\text { Interpreted the data and revised } \\
\text { the manuscript for intellectual } \\
\text { content }\end{array}$ \\
\hline $\begin{array}{l}\text { David } \\
\text { Leppert, } \\
\text { MD }\end{array}$ & $\begin{array}{l}\text { University Hospital } \\
\text { Basel, Switzerland }\end{array}$ & $\begin{array}{l}\text { Interpreted the data and revised the } \\
\text { manuscript for intellectual content }\end{array}$ \\
\hline $\begin{array}{l}\text { Stephane } \\
\text { Armand, } \\
\text { PhD }\end{array}$ & $\begin{array}{l}\text { Geneva University } \\
\text { Hospitals, } \\
\text { Switzerland }\end{array}$ & $\begin{array}{l}\text { Major role in the acquisition of data; } \\
\text { interpreted the data; and revised } \\
\text { the manuscript for intellectual } \\
\text { content }\end{array}$ \\
\hline $\begin{array}{l}\text { Patrice } \mathrm{H} . \\
\text { Lalive, MD }\end{array}$ & $\begin{array}{l}\text { Geneva University } \\
\text { Hospitals, } \\
\text { Switzerland }\end{array}$ & $\begin{array}{l}\text { Designed and conceptualized the } \\
\text { study; interpreted the data; and } \\
\text { revised the manuscript for } \\
\text { intellectual content }\end{array}$ \\
\hline
\end{tabular}

\section{References}

1. Sebastiao E, Sandroff BM, Learmonth YC, Motl RW. Validity of the timed up and go test as a measure of functional mobility in persons with multiple sclerosis. Arch Phys Med Rehabil 2016;97:1072-1077.

2. Allali G, Laidet M, Assal F, et al. Adapted timed up and go: a rapid clinical test to assess gait and cognition in multiple sclerosis. Eur Neurol 2012;67: $116-120$.

3. Lorefice L, Coghe G, Fenu G, et al. "Timed up and go" and brain atrophy: a preliminary MRI study to assess functional mobility performance in multiple sclerosis. J Neurol 2017;264:2201-2204.

4. Teunissen CE, Khalil M. Neurofilaments as biomarkers in multiple sclerosis. Mult Scler 2012;18:552-556.

5. Barro C, Benkert P, Disanto G, et al. Serum neurofilament as a predictor of disease worsening and brain and spinal cord atrophy in multiple sclerosis. Brain 2018;141: 2382-2391.

6. Kuhle J, Nourbakhsh B, Grant D, et al. Serum neurofilament is associated with progression of brain atrophy and disability in early MS. Neurology 2017;88: $826-831$.

7. Disanto G, Adiutori R, Dobson R, et al. Serum neurofilament light chain levels are increased in patients with a clinically isolated syndrome. J Neurol Neurosurg Psychiatry 2016;87:126-129.

8. Allali G, Laidet M, Herrmann FR, et al. Gait variability in multiple sclerosis: a better falls predictor than EDSS in patients with low disability. J Neural Transm (Vienna) 2016;123:447-450.

9. Tortorella C, Direnzo V, Taurisano P, et al. Cerebrospinal fluid neurofilament tracks fMRI correlates of attention at the first attack of multiple sclerosis. Mult Scler 2015; 21:396-401.

10. Ansai JH, Andrade LP, Nakagawa TH, et al. Cognitive correlates of timed up and go subtasks in older people with preserved cognition, mild cognitive impairment, and Alzheimer's disease. Am J Phys Med Rehabil 2017; 96:700-705. 


\section{Neurology \\ Neuroimmunology \& Neuroinflammation}

\section{Serum neurofilament light chains in MS: Association with the Timed Up and Go}

Gilles Allali, Jens Kuhle, Gautier Breville, et al.

Neurol Neuroimmunol Neuroinflamm 2020;7;

DOI 10.1212/NXI.0000000000000895

This information is current as of September 25, 2020

Updated Information \& Services

References

Subspecialty Collections

Permissions \& Licensing

Reprints including high resolution figures, can be found at:

http://nn.neurology.org/content/7/6/e895.full.html

This article cites 10 articles, 1 of which you can access for free at: http://nn.neurology.org/content/7/6/e895.full.html\#\#ref-list-1

This article, along with others on similar topics, appears in the following collection(s):

Disability

http://nn.neurology.org//cgi/collection/disability

Motor Control

http://nn.neurology.org//cgi/collection/motor_control

Multiple sclerosis

http://nn.neurology.org//cgi/collection/multiple_sclerosis

Information about reproducing this article in parts (figures,tables) or in its entirety can be found online at:

http://nn.neurology.org/misc/about.xhtml\#permissions

Information about ordering reprints can be found online:

http://nn.neurology.org/misc/addir.xhtml\#reprintsus

Neurol Neuroimmunol Neuroinflamm is an official journal of the American Academy of Neurology.

Published since April 2014, it is an open-access, online-only, continuous publication journal. Copyright

Copyright (C) 2020 The Author(s). Published by Wolters Kluwer Health, Inc. on behalf of the American

Academy of Neurology.. All rights reserved. Online ISSN: 2332-7812.

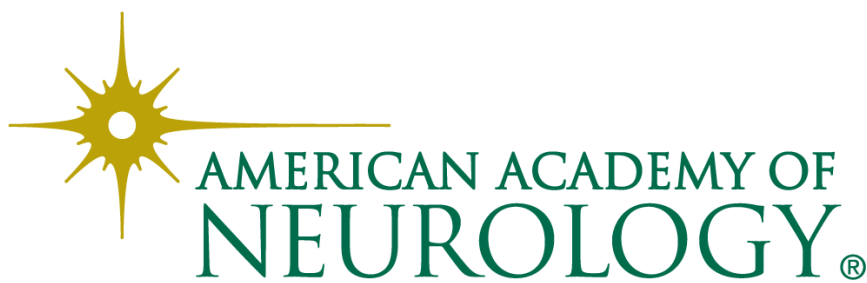

